\title{
Factors Enabling Collaboration in Management of Risks in Construction Projects: Stakeholders Perspective in Tanzania
}

\author{
Eng. Philemon, Z. Msomba ${ }^{1}$ \\ Doctoral student, \\ Department of Structural and Construction Engineering, \\ College of Engineering and Technology (COET), \\ University of Dar es Salaam, Tanzania
}

\author{
Dr. Matiko Samson ${ }^{2}$ \\ Lecturer, \\ Department of Structural and Construction Engineering, \\ College of Engineering and Technology (COET), \\ University of Dar es Salaam, Tanzania
}

\author{
Dr. Ramadhan, S. Mlinga \\ Lecturer, \\ Department of Structural and Construction Engineering, \\ College of Engineering and Technology (COET), \\ University of Dar es Salaam, Tanzania
}

\begin{abstract}
Increasingly effective management of risks in construction projects demand collaboration among contractual parties. This is evidenced by growth of literatures advocating for collaboration as an effective means to improve risk management in construction projects. Consequently different factors to enable collaboration have been suggested in literature. 24 enabling factors were identified through literature review. This paper evaluates these suggested factors with the purpose of identifying those which are critical for successful collaboration. The study then conducted questionnaire survey and pilot studies in construction industry to establish perception of practitioners on the enabling factors suggested by literature review. A questionnaire was sent out to 33 owners, 21 contractors, and 17 consultants. 14 factors were perceived to be critical enabling factors for collaboration. It was found that mutual trust, open communication, skills and Competence, commitment and information sharing among key project participants are highly perceived by respondents to be critical to successful collaboration in construction risk management
\end{abstract}

Keyword: Critical Enabler Factor, Risk Management, Collaboration, Construction Project

\subsection{INTRODUCTION}

A construction project usually involves a significant amount of work and a large number of participants; hence some sort of management and administrative framework is required to organize work and all of those who are involved. Much of the traditional project management (PM) literature has its focus on coping with risk and uncertainty in order to successfully deliver a project according to plan (Flanagan and Norman, 1993; Zwikael and Smyrk, 2015). Parties engaged in risk and uncertainty management (the project owner and/or representative, the design team and the project delivery entity) have usually done so separately and in isolation (Krystyna, 2015). The nature of complexity and competitive environment within the construction industry has proven these traditional approaches ineffective and led to increasing need collaborative approach. The management approach where all key players in any construction project in a multi-disciplinary team at both project management and design implementation levels collaboratively manage risks. This paper presents the factors which are considered critical to enable the required collaboration to haven. It uses literature to identify factors which have been empirically established to enable successful collaboration in management of risk in construction projects. It then discusses how these were rated by stakeholders in Tanzania. The paper eventually ranks these factors and 14 enabling factors were rated to be critical for enabling collaboration in management of risks.

\subsection{LITERATURE REVIEW}

Baiden et al. (2006) and Forques and Koskela (2009) state that the construction industry is composed of several types of organisations and groups of individuals with different characteristics, different cultures and style of management but with complementary skills and expertise needed for the delivery of a project. Alshawi and Faraj (2002) assert that a typical construction project involves the collaboration of a number of organizations, which are brought together for the duration of the project to form the 'project team'. Effective collaboration between the client, design team and contractor has been shown to enhance addressing risk and uncertainty through improving the dynamic capabilities of project participants (Davies et al, 2016). From a whole project perspective, co-coordinating and integrating different project parties is the most important task for project success. This can be facilitated by close and effective collaboration. Klemetti (2006) has identified collaboration as a key to construction success, but indicated that detailed methods of measuring collaboration performance are usually missing. This paper refers to critical enablers as factors that contribute to making it possible for collaboration in management of risk in construction projects.

In general, collaboration and teamwork studies in construction have looked into various factors that enable collaboration between project team members, such as trust, team flexibility and seamless operation (Ibrahim et al, 2011; Adetola et al 2011), team leadership (Cheung et al, 2001), communication 
and no blame culture (Moore and Dainty, 1999), project team communication (Perry and Sanderson, 1998), project members' participation (Leung et al, 2004), Interdependence and Appropriate team composition (Tarricone and Luca, 2002). However, the key factors that contribute to effective collaboration are problem solving and decision making (Guzzo and Salas, 1995). Based on the literature reviewed above, a total of twenty [24] factors are identified and [14] were identified as critical to enabling collaboration among project participants in risk management.

\subsection{METHODOLOGY}

The main part of the study was a questionnaire survey. It was employed to get perceptions of professionals in the Tanzanian construction industry on the factors considered critical to enable collaboration in the project. In order to measure the opinions of stakeholders, the Questionnaire was designed in a way that, respondent perceptions were measured in 5 point Likert scales $(5=$ most significant; $4=$ significant; $3=$ somehow significant; $2=$ less significant and $1=$ not significant). Respondents were asked to provide their opinion on the importance of the factors towards enabling successful collaborations in construction projects. Questionnaires were distributed to construction industry stakeholders during the Roads sector stakeholder conference held in October, 2016 in Dodoma-Tanzania. The participants were asked to fill in the questionnaires and submit them before the end of the conference. 71 completed questionnaires were properly responded to and qualified to be used for data analysis. It can be justified that the conference provided readily available random samples for the study. The representations were a mixture of professionals, including those dealing with policyformulation, design, construction, and clients of construction projects.

\subsection{Data analysis}

The rating and ranking of significant enabling factors for collaboration was carried out based on their mean rating values. In selecting the critical enabling factor the cut-off mean value was set to 2.5 . The data collected from the questionnaire were analyzed using Statistical Package for Social Science (SPSS) version10.0. The survey responses were analysed using the multi-attribute method (Mbachu, 2011). This involved computing the mean rating of all responses for a particular enabling factor. Respondents were asked to rate each enabling factor on a five-point Likert scale; rating point 5 being highest rating for most significant factors and rating point 1 being for factors that were perceived to be 'not significant at all'. The mean (M) that represents the average of the responses for a particular enabling factor was computed using the expression below.

$M=\left(\sum_{i=5}^{5} \mathrm{Wi}+\mathrm{fi}\right) \times \frac{100}{n} \%$
Where:

$M=\quad$ this is computed as summation of importance rating (i.e. the mean $(\mathrm{M})$ representative rating assigned to a specific critical enabling factor by all the respondents)

$w i=$ rating point, ranging from (1 to 5)

$f i=$ frequency of response; i.e. number of responses associating a critical enabling factor with a particular rating point

$n=\quad$ total number of respondents rating a particular critical enabling factor in the survey

\subsection{Measuring respondents' level of agreement}

To measure the agreement among respondents, the Coefficient of Variation (COV) was used. It was used because of its ability to compare relative variability of different responses, and indicate the level of validity and reliability of the research design, measuring instrument and findings (Elhag et al., 2005). The following expression was used to compute the COV.

$$
\operatorname{COV}=\frac{s}{X} X 100 \%
$$

Where:

$\mathrm{COV}=$ Coefficient of variation,

$\mathrm{S}=$ Standard deviation

$\mathrm{X}=$ Weighted mean of sample

\subsection{General Analysis of Respondents}

A total of 120 questionnaires were distributed out of which 76 were completed and returned, representing a 63 per cent return rate. However, only 71 questionnaires were fully usable. The remaining 5 were partial, incomplete or incorrectly filled and therefore, excluded from the analysis. Respondents of the all usable 71 questionnaire responses have at least a Bachelor degree in Engineering, Architecture or Quantity Surveying and have at least 5 years' experience in construction industry. This kind of qualification and experience is considered adequate to enable respondents to give credible responses. Among the respondents, $33(46.5 \%)$ are Clients, 21 (29.6\%) are Contractors and 17 (23.9\%) are Consultants.

\subsection{RANKING OF CRITICAL ENABLING FACTORS (CEFS)}

In selecting the critical enabling factors for collaboration the cut-off mean rating value is set at 2.50 , which represents "critical". The analysis of the questionnaire survey data was used to compute the mean ratings for each of the identified enabling factors. Among the 24 factors identified in the literature review and sent to stakeholders for opinion only 14 factors were considered to be critical enabling factors (CEFs). These are factors whose mean ratings are ranging from 2.50 to 4.48 indicated that all respondents consider these 14 enabling factors critical for collaboration in management of risk in construction projects. Table 1and 2 summarizes the results of the analysis of the relative importance and variance of the enabling critical factors for collaboration in risk management in construction projects. 
Table1 Ranking of critical enabling factors for collaboration in management of risk by the clients and contractors

\begin{tabular}{|c|c|c|c|c|}
\hline \multirow[b]{2}{*}{ Enabling Factor } & \multicolumn{2}{|c|}{ Clients } & \multicolumn{2}{|c|}{ Contractors } \\
\hline & 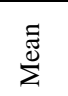 & $\stackrel{\check{Z}}{\check{I}}$ & $\stackrel{\Xi}{\Xi}$ & $\stackrel{y}{\stackrel{\Xi}{*}}$ \\
\hline Trust among participants & 4.42 & 2 & 4.19 & 3 \\
\hline $\begin{array}{l}\text { Open Communication about every aspect of } \\
\text { the project }\end{array}$ & 4.76 & 1 & 4.18 & 4 \\
\hline $\begin{array}{l}\text { Skill/Competence to each and all key } \\
\text { participants }\end{array}$ & 4.27 & 4 & 4.62 & 1 \\
\hline $\begin{array}{l}\text { Commitment of each and all project } \\
\text { participants }\end{array}$ & 4.36 & 3 & 4.17 & 5 \\
\hline $\begin{array}{l}\text { Information sharing to enable common } \\
\text { understanding of project circumstances }\end{array}$ & 4.23 & 6 & 4.14 & 7 \\
\hline Good relationships & 4.21 & 7 & 4.01 & 8 \\
\hline $\begin{array}{l}\text { Mutual understanding of goals, } \\
\text { responsibilities and constraints of the project }\end{array}$ & 4.24 & 5 & 3.81 & 11 \\
\hline Proactive and joint problem solving & 4.06 & 8 & 4.16 & 6 \\
\hline $\begin{array}{l}\text { Knowledge sharing throughout the project } \\
\text { cycle }\end{array}$ & 3.85 & 11 & 4.24 & 2 \\
\hline Fair distribution of responsibility & 3.88 & 10 & 3.86 & 10 \\
\hline $\begin{array}{l}\text { Flexibility in project planning and } \\
\text { implementation }\end{array}$ & 3.91 & 9 & 3.44 & 12 \\
\hline Fairy drafted contracts & 3.55 & 12 & 4.00 & 9 \\
\hline Seamless operation & 3.33 & 15 & 3.43 & 13 \\
\hline No blame culture among participants & 3.39 & 14 & 3.37 & 15 \\
\hline Risk allocation & 3.45 & 13 & 3.31 & 16 \\
\hline Risk and uncertainty & 3.32 & 16 & 3.40 & 14 \\
\hline Finance & 3.30 & 18 & 3.29 & 17 \\
\hline Interdependences & 3.29 & 20 & 3.15 & 18 \\
\hline Technology & 3.25 & 22 & 3.00 & 19 \\
\hline Globalization demand & 3.22 & 23 & 2.93 & 20 \\
\hline Legal and regulatory Framework & 3.28 & 21 & 2.76 & 23 \\
\hline Appropriate team composition & 3.30 & 19 & 2.83 & 22 \\
\hline Shared goals and objectives & 3.31 & 17 & 2.65 & 24 \\
\hline Competition & 3.12 & 24 & 2.90 & 21 \\
\hline
\end{tabular}

Table1 Ranking of critical enabling factors for collaboration in management of risk by the consultants and overall ranking (clients, contractors and consultants)

\begin{tabular}{|c|c|c|c|c|c|}
\hline \multirow[b]{2}{*}{ Enabling Factor } & \multicolumn{2}{|c|}{ Consultants } & \multirow{2}{*}{$e^{0}$} & \multicolumn{2}{|c|}{$\begin{array}{c}\text { Overall } \\
\text { Ranking }\end{array}$} \\
\hline & $\sum_{\Sigma}^{\Xi}$ & 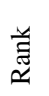 & & 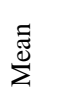 & 兰 \\
\hline Trust among participants & 4.42 & 1 & 14.6 & 4.42 & 1 \\
\hline $\begin{array}{l}\text { Open Communication about every } \\
\text { aspect of the project }\end{array}$ & 4.36 & 3 & 14.5 & 4.36 & 3 \\
\hline $\begin{array}{l}\text { Skill/Competence to each and all } \\
\text { key participants }\end{array}$ & 4.29 & 5 & 13.0 & 4.29 & 5 \\
\hline $\begin{array}{l}\text { Commitment of each and all } \\
\text { project participants }\end{array}$ & 4.41 & 2 & 12.9 & 4.41 & 2 \\
\hline $\begin{array}{l}\text { Information sharing to enable } \\
\text { common understanding of project } \\
\text { circumstances }\end{array}$ & 4.12 & 6 & 12.5 & 4.12 & 6 \\
\hline Good relationships & 4.35 & 4 & 13.0 & 4.35 & 4 \\
\hline $\begin{array}{l}\text { Mutual understanding of goals, } \\
\text { responsibilities and constraints of } \\
\text { the project }\end{array}$ & 4.06 & 8 & 17.3 & 4.06 & 8 \\
\hline 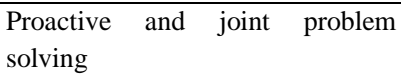 & 3.94 & 11 & 18.0 & 3.94 & 11 \\
\hline $\begin{array}{l}\text { Knowledge sharing throughout the } \\
\text { project cycle }\end{array}$ & 4.07 & 7 & 20.0 & 4.07 & 7 \\
\hline
\end{tabular}

\begin{tabular}{|l|c|c|c|c|c|}
\hline Fair distribution of responsibility & 3.88 & 12 & 15.7 & 3.88 & 12 \\
\hline $\begin{array}{l}\text { Flexibility in project planning and } \\
\text { implementation }\end{array}$ & 4.00 & 10 & 20.4 & 4.00 & 10 \\
\hline Fairy drafted contracts & 4.01 & 9 & 16.0 & 4.01 & 9 \\
\hline Seamless operation & 3.65 & 13 & 30.1 & 3.65 & 13 \\
\hline $\begin{array}{l}\text { No blame culture among } \\
\text { participants }\end{array}$ & 3.60 & 14 & 21.1 & 3.60 & 14 \\
\hline Risk allocation & 3.45 & 15 & 21.0 & 3.45 & 15 \\
\hline Risk and uncertainty & 3.26 & 16 & 19.2 & 3.26 & 16 \\
\hline Finance & 3.10 & 18 & 22.5 & 3.10 & 18 \\
\hline Interdependences & 3.15 & 17 & 23.2 & 3.15 & 17 \\
\hline Technology & 2.92 & 19 & 20.8 & 2.92 & 19 \\
\hline Globalization demand & 2.85 & 21 & 21.6 & 2.85 & 21 \\
\hline Legal and regulatory Framework & 2.88 & 20 & 22.3 & 2.88 & 20 \\
\hline Appropriate team composition & 2.69 & 22 & 19.7 & 2.69 & 22 \\
\hline Shared goals and objectives & 2.57 & 23 & 23.5 & 2.57 & 23 \\
\hline Competition & 2.54 & 24 & 24.2 & 2.54 & 24 \\
\hline
\end{tabular}

The result in Table 1 indicates the overall rating and ranking of the enabling critical factors for collaboration in management of risk in construction projects as perceived by the respondents in descending order. Trust among project participants, Open communication, Skill/Competence of each and all key participants, Commitment of each and all project participants, Information sharing to enable common understanding of project circumstances, Good relationships, Mutual understanding of goals, responsibilities and constraints of the project. Other enabling factors are Proactive and joint problem solving, Knowledge sharing throughout the project cycle, Fair distribution of responsibility, Flexibility in project planning and implementation to enable the accommodation of eventualities, Fair drafted contract, Seamless operation and No blame culture among participants. Coefficient of variation (COV) for most of enabling factors achieved relatively low COV value less than $25 \%$, which means results gained high agreement from participants. Coefficient of variation (COV) for seamless operation is $30.1 \%$, this may be resulted from the traditional method experienced by participants for implementation of construction projects within which every project participants look on own objectives. Therefore the importance of seamless operation as enabling factor for collaboration was perceived differently by respondents causing differences in opinions from respondents.

\subsection{Trust among participants}

Trust is the foundation of effective collaboration. The enabling factor has been ranked in the first position in the overall ranking with mean value equal to 4.48 and COV value of 14.6 $\%$. Essentially, trust is confidence in another's goodwill and integrity as well as the belief in another's ability and credibility, and is associated with such qualities as being honest, faithful and truthful. Trust is a primary factor in how people work together, listen to one another, and build effective relationships. Trust is a critical link to all good relationships, both personal and professional.. Based on relational exchange theory (RET), trust among participants can develop an effective coordination mechanism and plays an important role in preventing opportunism, facilitate risk management, reducing transaction costs, simplifying decision making and promoting the structure of the cooperation stable. These findings have been supported by Wang and Huang (2006) who 
explain that lack of trust creates cynicism, doubt, and anxiety that lead to "time off-task" speculation and generally low energy and productivity. When people don't trust each other, they don't come toward something; they pull back and withdraw instead. They doubt rather than cooperate. Trust and respect are the bedrock of collaboration and are the key to building a commitment to collective goals

\subsection{Open communication}

Project risk management is all about communications. Good communication between key participants is most important for the success of every construction project. In overall ranking open communication was ranked in the second position by the respondents with mean equal to 4.35 and $\mathrm{COV}$ value of $14.5 \%$.There is no collaboration without effective communication. Intuitively and as confirmed in the findings, communication is a prerequisite for successful project management and project risk management to align. The goal of project communications is to ensure timely and appropriate collection, storage, distribution and generation of project information. Communication involves sharing relevant information between project participants. Poor communication has been shown to be one of the most common project risks (Ceric, 2003). It is usually assumed that all participants cooperate and exchange information in order to achieve project's goals project's goals. Well-functioning communication in construction projects is highly relevant for managing project risks. Proper communication channel between the various parties must be established during the project planning. Every project should include a communication management plan - a document that guides projects communications. This plan should be part of overall project plan. The type of communication will vary with the needs of the project. Proper communication ensures that the right information is passed to the right persons or organizations thereby mitigating their possible impact on project progress. Problems with communication can lead to serious misunderstanding and therefore, risks in the execution of the projects. These findings are supported by Sievert (1986), who says that a high percentage of the problems in working relationships may be attributed to poor communication. It is usually assumed that all participants cooperate and exchange information in order to achieve

\subsection{Skill/Competence to each and all key project participants}

The enabling factor has been ranked in the third position in the overall ranking with mean value equal to 4.35 and $\mathrm{COV}$ value of $13.0 \%$. Project success is dependent on having the right personnel on the project in a labour intensive industry like construction. The finding has been supported by Hatush and Skitmore (1997) who explained that the correct choice of personnel which covers the manpower resources available on the project, the qualification, experience, skills and expertise, organizational structure as well as the management capabilities of key personnel has much influence on collaboration in risk management. Also the finding is in line with the studies of Geraldi et al (2010) and Moe and Pathranarakul (2006) who established a positive relationship among team competency with skills and effective construction risk management.

\subsection{Commitment of each and all project participants}

Commitment encompasses the creation of and commitment to common goals for the project team and a willingness to achieve them. The enabling factor has been ranked in the fourth position in the overall ranking with mean value equal to 4.32 and COV value of $12.9 \%$. It has been ranked in the third position by clients' respondents with mean equal to 4.36. Also it has been ranked in fifth position by contractors' respondents with men equal to 4.17 and in second position by consultants' respondents with mean equal to 4.41. Commitment is important in any relationship. It is the value that galvanises diverse entities so that all can work together unilaterally and seamlessly. There is nothing that enforces the commitments in the relationship except the integrity of the people involved. Without it, there is no bond and no common purpose, commitment is the force that drives the relationship forward, toward a mutually desirable goal that usually points to growth and /or profitability. Important aspect of this commitment are likely to how much all the project team members take responsibilities for achieving their task in line with this, and the degree to which they share understanding of their project objectives. These findings are in line with the work of MeiYung et al (2004) who argue that affective commitment improves the project performance because people are more attached and involved in the project, and also want to stay in the organizational for the particular project. Also the findings have been supported by Fowler and Horan (2007) who identified a combination of top management commitment and project team commitment as a force driving the success development of IS projects, and revelled that a high level of commitment is promoted and maintained by means of the communication techniques used by the project manager, such as regularly issuing status reports and direct contact with the people involved in the project development.

\subsection{Information sharing to enable common understanding of project circumstance}

The enabling factor has been ranked in the fifth position in the overall ranking with mean value equal to 4.20 and $\mathrm{COV}$ value of $12.5 \%$. Information sharing is very important factor in building collaboration between project participants. It is necessary that clear and authentic information is passed at the appropriate time, place and to the right person during project execution. More so, flow of information which maybe downward or upward information is an essential part of project to be conceived. This finding is supported by Zahedi and Babar (2014) who explain that the importance of information sharing was emphasized to build collaboration strength, shared understanding, and common ground, particularly when not colocated. Cooperative and collaborative activities within an organization often involve information sharing. Hertzum (2008) emphasized that information sharing has a central role in collaboration.

\subsection{Good relationships}

The enabling factor has been ranked in the sixth position in the overall ranking with mean value equal to 4.18 and COV value of $13.0 \%$. Relationships are generally understood to be the state of affairs existing between people having associations or dealings. For a project team, good relationships deal with a set 
of connections and interactions with individuals or groups which in turns facilitate the project execution during its life cycle. Good relationship between project participants is important for collaboration irrespective of whether these people or groups are directly or indirectly affected by the project outcome. Traditionally adversarial relationships make coordination and co-operation difficult. Adversarial relationships also restrict the sharing of experiences and information. Project success or failure always depends partly on the effectiveness (or ineffectiveness) of key relationships during the project life cycle.

\subsection{Mutual understanding of goals, responsibilities and constraints of the project}

The enabling factor has been ranked in the seventh position in the overall ranking with mean value equal to 4.07 and $\mathrm{COV}$ value of $13.0 \%$. It has been ranked in the fifth position by clients' respondents with mean equal to 4.24. Mutual understanding of project goals among project team members will facilitate creating an environment where they are all willing to contribute and participate in collaboration in order to promote and nurture a positive, effective team environment. Project team members must be flexible enough to adapt to cooperative working environments where goals are achieved through collaboration and social interdependence rather than individualistic, competitive goals.

\subsection{Proactive and joint problem solving}

The enabling factor has been ranked in the eighth position in the overall ranking with mean value equal to 4.04 and $\mathrm{COV}$ value of $18.0 \%$. Effective collaboration in management of risk is not achieved by simply reacting to problems. Joint problem solving is widely adopted and the tendency to 'blame others' is replaced in effective team working with a direction of effort toward understanding problems and finding solutions. The project team should work to identify risks in advance and to develop strategies and plans to manage them. Plans should be developed to correct problems if they occur. Anticipating potential risks and having well-formed plans in place ahead of time shortens the response time in a crisis and can limit or even reverse the damage caused by the occurrence of a risk.

The key to proactive RM processes lies in the project team's ability to mobilize the knowledge and expertise of its employees regarding risk mitigation to provide the decision makers accurate and timely information about potential risks. The research finding is in line with Latham's (1994) "Constructing the team" report which revealed that segregation between participants and roles is one of the principal causes of poor performance. Joint problem solving and interaction between the project participants, particularly early in the construction process promotes buildability, and this reduces the likelihood of variations, defects and associated reworking, delays, additional costs and conflicts. This factor covers harmonious working relationships which according to Soetanto et al. (2001) is an essential ingredient of project success, and also covers the level and quality of communication that occurs between participants.

\subsection{Knowledge sharing throughout the project cycle}

The enabling factor has been ranked in the ninth position in the overall ranking with mean value equal to 4.01 and $\mathrm{COV}$ value of $20.0 \%$. Knowledge sharing enhances communication within project team, resulting in a better understanding and sharing of project objectives. It provides with best practice awareness, lessons learned, project management methodologies and techniques. From this perspective a project meant to be a ground for knowledge creation, utilisation and sharing, where collaboration is critical for project performance and success. Knowledge sharing can have a great influence on reducing organizations' risks. A company cannot manage its risks effectively if it cannot manage its knowledge, many projects failed due to lack of knowledge among the project team or lack of knowledge sharing during project progress. In fact, without knowledge sharing as a tool to communicate risks among members of a project team, RM might suffer from ineffectiveness and inefficiencies. Since knowledge is created in a project by the project team member completing the task. Therefore, an organization needs to ensure that knowledge from one project is available for use on future projects to reduce rework. Furthermore, the application of knowledge sharing processes to support RM processes has the potential of iteratively mitigating the probability of risks, thereby raising the probability of successful project execution. It is important that the organization prioritizes knowledge infusion of RM which, would require the creation, capturing and sharing of knowledge related to potential risks to key assets of stakeholders.

\subsection{Fair distribution of responsibilities}

The enabling factor has been ranked in the tenth position in the overall ranking with mean value equal to 3.87 and COV value of $15.7 \%$. In fair distribution of responsibilities project completion risks, design risks, construction and commissioning risk, as well as other residual risks, will be a factor for all of the key project participants. It is important to appreciate that principles of equity and fairness in distribution of responsibilities should apply in allocating risk in contracts, simply allocating risk to the weaker party who is less likely to present a strong bargaining position in the negotiation process risks an unnecessary escalation in the cost of the project, as the so-called weaker party will perceive project risks as being onerous and will build such risks into its cost projections for delivering services. Unequal or overwhelmingly one-sided contracts, throwing all of the major risks and responsibilities on to one project participant, can result in a breakdown of relationships during the course of a project, rather than making for a smooth collaboration process throughout the term of construction. This will ultimately translate into acrimony, claims and difficulty in achieving an overall successful project, as one party or the other perceives that it is being taken advantage of and that it has signed a less than fortuitous contract.

\subsection{Flexibility in project planning and implementation}

The enabler factor has been ranked in the eleventh position in the overall ranking with mean value equal to 3.79 and $\mathrm{COV}$ value of $20.4 \%$. It has been ranked in the ninth position by clients' respondents with mean equal to 3.91. Also it has been 
ranked in twelfth position by contractors' respondents with men equal to 3.44 and in tenth position by consultants' respondents with mean equal to 4.00 . In practice, the construction inherently possesses a certain degree of flexibility as owners' requirements or rules and regulations change. Most of existing approaches to flexibility are reactive, such as change orders and as-built plans. Other practice, like shortterm planning may work but are still inadequate to deal with increasing project complexity. In addition, some project delivery systems such as fast-track, phased construction, Design-Build are thought to inject certain flexibility to construction projects. The development of information technologies such as computer-aid design tools, project management software, Building Information Modeling (BIM) have been changing the way of delivering construction project to be more flexible

\subsection{Fairy drafted contracts}

The enabler factor has been ranked in the twelfth position in the overall ranking with mean value equal to 3.79 and $\mathrm{COV}$ value of $16.0 \%$. It has been ranked in the twelfth position by clients' respondents with mean equal to 3.55 . Also it has been ranked in ninth position by contractors' respondents with men equal to 4.00 and in ninth position by consultants' respondents with mean equal to 4.01. Contracts are an early opportunity to anticipate, define and deal with potential issues and thereby avoid risks consequences. Since contracts are the medium within which project risks are allocated and dealt with, the form of contract used for each project is critical to the potential for optimum performance and production. Risks associated with construction projects should often be clearly allocated to the responsible party through the contract conditions. When the contact conditions related to risk allocation are vague and are not adequately written then several problems may be encountered, in view of the fact that risk is related to every aspects of the project. If any conflict is faced and the contract conditions does not provide sufficient assistant to resolve the conflict then this may lead to endless disputes. Contract conditions should not be subject to interpretations, yet they should be clearly written and mutually understood by all parties.

\subsection{Seamless operation}

The enabler factor has been ranked in the thirteenth position in the overall ranking with mean value equal to 3.44 and $\mathrm{COV}$ value of $30.1 \%$. It has been ranked in the fourteenth position by clients' respondents with mean equal to 3.33 . Also it has been ranked in thirteenth position by contractors' respondents with men equal to 3.43 and in thirteenth position by consultants' respondents with mean equal to 3.65. The COV value obtained under this enabler factor indicate that there is no agreement between the perceptions from these groups. The findings reveal that seamless operation with no organisational defined boundaries as a vital indicator of team collaboration practice in which the boundaries between individuals are diminished and team members work collaboratively towards mutually beneficial outcomes for the project. This presents a climate where organisations in the construction industry have to collaborate and share knowledge, skills and expertise in order to survive in a competitive market (Kajewski, 2003).
Effective collaboration in management of risks ensures for comprehensive and continuous cooperation across the interfaces, thus surmounting the boundaries between parties by facilitating a collaborative culture and communication throughout the project life cycle. Not doing so, may result in the project surrendering to the complex interfaces and boundaries between parties.

\subsection{No blame culture among participants}

The enabler factor has been ranked in the fourteenth position in the overall ranking with mean value equal to 2.48 and $\mathrm{COV}$ value of $21.1 \%$. It has been ranked in the thirteenth position by clients' respondents with mean equal to 3.39. Also it has been ranked in fourteenth position by contractors' respondents with men equal to 3.29 and in fourteenth position by consultants' respondents with mean equal to 2.88 . The establishment of a 'no fault - no blame' culture underpins the collaboration in management of risk in construction projects. It involves a commitment from each of the project participants that, where there is an error, mistake or poor performance, the project participants will not attempt to assign blame but will rather accept collective responsibility and its consequences and agrees a remedy or solution which is best-for-project. If the project participants disagree, they must work together to resolve issues in a best-for-project manner.

\subsection{CONCLUSION}

This study has established factors perceived as critical for successful collaboration in management of risk in construction projects. Results of a multi-attribute analysis showed that fourteen critical enabling factors are, mutual trust among project participants, open communication, skill/Competence to each and all key participants, commitment of each and all project participants and information sharing to enable common understanding of project circumstance. Coefficient of variation (COV) analysis indicated high level of agreement amongst survey participants in the rank-ordering of the relative importance of the identified factors. It is recommended to pay attention to these critical enabling factors at the time of project planning and execution so that project participants can collaboratively manage project risks.

\section{REFERENCES}

[1] Alshawi, M. and Faraj, I..'Integrated construction environments: technology and implementation," Construction Innovation, Vol. 2, No.1, pp. $33-51,2002$.

[2] Baiden, B.K., Price, A.D.F. and Dainty, A.R.J. "The extent of team integration within construction projects,", International Journal of Project Management, Vol. 24, No. 2, pp. 13 - 23, 2006.

[3] Ceric, A., A Framework for Process-Driven Risk Management in Construction Projects, $\mathrm{PhD}$ Thesis, Research Institute for the Built and Human Environment, School of Construction and Property Management, University of Salford, Salford, 2003.

[4] Davies, A.; Dodgson, M.; Gann, D.’'Dynamic capabilities in complex projects," The case of London heathrow terminal 5. Project Management Journal, Vol. 47, pp. 26-46, 2016.

[5] Elhag, T. M. S., Boussabaine, A. H., and Ballal, T. M. A. "Critical determinants of construction tendering costs," Quantity surveyors' standpoint. International Journal of Project Management, Vol.23, No.7, pp.538-545, 2005.

[6] Flanagan, R.; Norman, G. Risk Management and Construction; Blackwell Science Publications: Oxford, UK, 1993. 
[7] Forgues, D. and Koskela, L. "The influence of a collaborative procurement approach using integrated design in construction on project team performance," International Journal of Managing Projects in Business, Vol. 2, No. 3, pp.370 - 385, 2009.

[8] Fowler, J. J., and Horan, P. "Are Information Systems' Success and Failure Factors Related?" An Exploratory Study, Journal of Organizational and End User Computing, Vol. 19, No. 2, pp.122, 2007.

[9] Geraldi, J. G., Lee - Kelley, L., and Kutsch, E. "The Titanic sunk, so what? Project manager response to unexpected events," International Journal of Project Management, Vol. 28, No. 6, pp. $547-558,2010$

[10] Hatush, Z and Skitmore, M. R. "Assessment and evaluation of contractor data against client goals using pert approach," Construction Management and Economics Vol.15, No.4: pp. 327- 340, 1997.

[11] Hertzum, M. "Collaborative information seeking, The combined activity of information seeking and collaborative grounding," Information Processing and Management Vol. 44, No. 2, pp. 957-962, 2008.

[12] Kajewski, S., Chen, E., Brewer, G., Gameson, R., Gajendran, T., Kolomy, R., Lenard, D., MacKee, J., Martins, R., and Sher, W., McCabe, K and J. McCann, Project Team Integration: Communication, Coordination and Decision Support. Part A: Scoping Studies. Technical Report2001-008-C-04, CRC-CI, Queensland University of Technology, 2003. [Online] Available: $\quad$ http://eprints.qut.edu.au/17874/1/17874.pdf. (Accessed on July, 2016)

[13] Klemetti, A. Risk Management in construction Projects, Helsinki University of Technology: Finland, 2006.

[14] Krystyna, A., "Building Information Modelling: An Innovative Way to Manage Risk in Construction Projects," International Journal of Contemporary Management Vol.14, No. 3, pp. 2340, 2015.

[15] Latham, M. Constructing the team, Final report of the government/industry review of procurement and contractual arrangements in the United Kingdom construction industry, London, HMSO, Department of Environment, 1994.

[16] Mbachu, J."Sources of contractor's payment risks and cash flow problems in the New Zealand construction industry": Project team's perceptions of the risks and mitigation measures. Construction Management and Economics, Vol. 29, No. 10, pp. 1027-1041, 2011.

[17] Mei-Yung, L., Chong, A., Ng, S. T., and Cheung, M. C. K. "Demystifying stakeholders' commitment and its impacts on construction projects," Construction Management and Economics, Vol. 22, No.7, pp.701-715, 2004.

[18] Moe, T. L., and Pathranarakul, P., "An integrated approach to natural disaster management: public project management and its critical success factors". Disaster Prevention and Management, Vol.15, No.3, pp.396-413, 2006.

[19] Sievert, R. W. " Communication: an important construction tool," Project Management Journal, Vol.17. No.5, pp. 77-82, 1986.

[20] Soetanto, R., Proverbs, D. G. and Holt, G. D. "Achieving quality construction projects based on harmonious working relationships: clients' and architects' perceptions of contractor performance," International Journal of Quality and Reliability Management, Vol.18, No. 4/5, pp.528-548, 2001.

[21] Wang, X and J. Huang, J. "The Relationships between Key Stakeholders' Project Performance and Project Success: Perceptions of Chinese Construction Supervising Engineers," International Journal of Project Management, Vol. 24, No. 3, 2006, pp. 253-260, 2006.

[22] Zahedi, M., and Babar, M.A. Knowledge sharing for common understanding of technical specifications through artifactual culture, Proceedings of the $18^{\text {th }}$ international Conference on Evaluation and Assessment in Software Engineering, Article No11, London, England, United Kingdom-May 13-14, 2014.

[23] Zwikael, O.; Smyrk, J " Project governance: Balancing control and trust in dealing with risk," International Journal of Project Management, Vol. 33,pp. 852-862, 2015 